\title{
A produção de tabaco no Brasil: um estudo com base na teoria da localização e do crescimento regional de Douglass North
}

\author{
Eliane de Souza Santos ${ }^{1}$ \\ Cidonea Machado Deponti ${ }^{2}$
}

\begin{abstract}
Resumo
Esta pesquisa se trata de uma análise sobre a trajetória sócio histórica da produção de tabaco no Brasil. Diante da história e do papel desta cultura para a economia, o objetivo geral do estudo é realizar uma análise sob a ótica da teoria da localização e do crescimento regional de Douglass North. A pesquisa justifica-se pelo fato de que a cultura do tabaco está presente no desenvolvimento das regiões produtoras no país. Para tanto, utiliza-se a metodologia de caráter descritivo-exploratória. A revisão bibliográfica foi embasada em artigos científicos de autores que investigam sobre o tema, além de dados e informações do Sindicato Interestadual da Indústria do Tabaco (SINDITABACO). Diante da análise dos dados, entende-se a importância desta cultura em uma trajetória histórica de desenvolvimento das regiões produtoras, e principalmente, de inserção da produção no mercado internacional, com a oferta de um produto diferenciado e com qualidade brasileira. Entretanto, é possível concluir que em termos de desenvolvimento regional, é necessária a diversificação produtiva do território, pois, a diversificação é uma condição de segurança para a região.
\end{abstract}

Palavras-Chave: Tabaco. Institucionalismo Econômico. Localização. Desenvolvimento Regional.

\section{Tobacco production in Brazil: a study based on Douglass North's theory of location and regional growth}

\begin{abstract}
This research is an analysis of the socio-historical trajectory of tobacco production in Brazil. Given the history and role of this culture for the economy, the general objective of the study is to carry out an analysis from the perspective of Douglass North's theory of location and regional growth. The research is justified by the fact that the tobacco culture is present in the development of the producing regions in the country. For this, the methodology of a descriptive-exploratory character is used. The bibliographic review was based on scientific articles by authors investigating the subject, in addition to data and information from the SINDITABACO. In view of the data analysis, the importance of this culture is understood in a historical trajectory of development of the producing regions, and mainly, of insertion of production in the international market, with the offer of a differentiated product with Brazilian quality. However, it is possible to conclude that in terms of regional development, productive diversification of the territory is necessary, since diversification is a condition of security for the region.
\end{abstract}

Keywords: Tobacco. Economic Institutionalism. Institutions. Regional Development.

\section{Introdução}

A cadeia produtiva do tabaco envolve uma série de atores que participam dos vários estágios de produção, comercialização, processamento e exportação, o que representa um importante setor agrícola para o país, formado por inúmeros produtores rurais que usam a mão

${ }^{1}$ Economista (Unisc). https://orcid.org/0000-0002-0185-6965 E-mail: eliane santos93@hotmail.com

2 Doutorado em Desenvolvimento Rural (UFRGS). Pós-Doutorado em Sociologia do Desenvolvimento. Professora do Programa de Pós-Graduação em Desenvolvimento Regional (PPGDR/UNISC). http://orcid.org/0000-0001-8833-1450 E-mail: cidonea@yahoo.com.br 
de obra familiar, e um conjunto de empresas que geram empregos, renda e arrecadação tributária (SAITO et al, 2018). “A compreensão do modo como os diferentes agentes envolvidos interagem no processo produtivo é extremamente importante quando se analisa o agronegócio do tabaco" (WEISS, 2015, p. 18).

A cultura do tabaco faz parte da história do Brasil, contribuindo para o desenvolvimento das regiões produtoras, e para o destaque do país no cenário internacional, pois, o país é o segundo maior produtor mundial de tabaco e líder em exportações desde o ano de 1993. Para tanto, dispõe de fatores que determinam a competitividade da produção, esses fatores são: terras férteis e agricultáveis, água, clima favorável, mão de obra barata, mecanização e pesquisa agropecuária (HILSINGER, 2016)

De acordo com North (1977), o crescimento de uma região é consequência dos resultados da sua base de exportação, deste modo, para compreender tal crescimento se faz necessário analisar os fatores locais que viabilizaram o desenvolvimento de produtos primários. “Historicamente, em uma região jovem, a criação de um novo produto de exportação, ou a expansão de um já existente, tem resultado no influxo de investimento de capital na indústria de exportação" (NORTH, 1977, p. 347).

Atualmente, o tratamento dado ao agronegócio brasileiro que tem sido focado nos sistemas de produção de soja, da cana-de-açúcar e das carnes bovina, suína e de aves, mas existem outros sistemas de produção que trazem inovações organizacionais. Como por exemplo, a cadeia produtiva do tabaco (BUAINAIN; FILHO, 2009). De acordo com Beling (2006, p. 22), não somente no Brasil, mas em outros países, o tabaco pode ser observado como um "difusor de tecnologias para outras culturas, inclusive para a produção de alimentos, contribuindo para o aumento dos níveis de produtividade, de conservação do solo e aprimoramento das práticas em segmentos como arroz, milho e feijão".

Diante disso, o objetivo principal deste estudo é identificar a trajetória sócio histórica da produção de tabaco no Brasil e realizar uma análise sob a ótica da teoria da localização e do crescimento regional de Douglass North. Pois, com base nos pressupostos das teorias de North, existe uma sequência típica de estágios que as regiões percorrem ao longo do seu desenvolvimento, e essa sequência pode ser observada na história da cultura do tabaco no país.

Define-se pesquisa como o procedimento racional e sistemático que tem como finalidade proporcionar respostas aos problemas que são apresentados. A pesquisa é solicitada quando não se têm informação suficiente para responder ao problema, ou se encontram de forma desordenada que não possa ser devidamente relacionada ao problema (GIL, 1991). A 
metodologia utilizada tem como natureza a pesquisa descritivo-exploratória e será desenvolvida a partir da revisão bibliográfica embasada em artigos científicos de autores que investigam sobre o tema. E ainda, a abordagem teórica de Douglass North.

Para atender o objetivo principal, além deste texto de introdução, o artigo está estruturado em um levantamento histórico sobre a trajetória da cultura do tabaco no Brasil atrelado a sequência de estágios para o desenvolvimento das regiões, seguido de uma análise a partir do conceito de path dependence abordado pela Nova Economia Institucional, e ainda, uma crítica ao trabalho de North. E por fim, as considerações finais.

\section{História do tabaco no Brasil}

A cultura do tabaco é de origem americana, sendo cultivada pelos indígenas da América do Sul e do Norte, segundo historiadores. Uma das hipóteses é que a planta teria surgido nos vales orientais dos Andes Bolivianos, difundindo-se pelo território brasileiro por meio das migrações indígenas. No início do século XVI, os primeiros portugueses a desembarcarem no Brasil encontraram o cultivo de tabaco em quase todas as tribos indígenas, onde o consumo era feito de diferentes maneiras (comido, bebido, mascado, aspirado e fumado), mas o hábito de fumar era predominante (SINDITABACO, 2019).

De planta sagrada dos índios, o tabaco passou a ser um produto comercial das colônias europeias e do Brasil. Assim, o cultivo e o comércio de tabaco no Brasil colonial tiveram importância destacada, passando a figurar entre os principais produtos exportados durante o período do Império. Esta importância ficou marcada no brasão das Armas da República, onde o tabaco e o ramo de café constituem o coroamento deste símbolo da nacionalidade brasileira (SINDITABACO, 2019).

Com base na teoria da localização e na teoria do crescimento regional de Douglass North, existe uma sequência típica de estágios que as regiões percorrem ao longo do seu desenvolvimento, sendo que o primeiro estágio da história econômica da maioria das regiões pode ser considerado "[...] uma fase de economia de subsistência, autossuficiente, na qual existe pouco investimento ou comércio. A camada principal da população, a agrícola, localiza-se de acordo apenas com a distribuição dos recursos naturais" (NORTH, 1977, p. 334). Cabe notar que quando os portugueses chegaram ao Brasil, o tabaco era produzido para atender o consumo dos índios, somente em um segundo momento o produto passou a integrar o comércio. 
A partir da colonização portuguesa, o tabaco constituiu-se como um dos produtos usados como moeda de troca na aquisição de escravos vindos do continente africano (VENDRUSCOLO, 2017). Em 1570, conforme o mercado foi se constituindo, os colonos portugueses iniciaram o cultivo do tabaco buscando o abastecimento do mercado europeu. E assim, o produto se tornou um vício generalizado, sendo necessário aumentar a produção no continente americano (HILSINGER, 2016).

Neste período, o tabaco brasileiro era cultivado principalmente na região litorânea da Bahia, onde as condições eram favoráveis para a produção de fumos escuros. A região se portou como a principal produtora até 1950, entretanto, os charutos do Recôncavo Baiano continuam sendo reconhecidos no exterior pela sua qualidade (BUAINAIN; FILHO, 2009).

Com a chegada dos colonos alemães, italianos e poloneses, o tabaco se tornou uma fonte de renda, e assim, a produção alastrou-se para os estados de Minas Gerais, São Paulo, Goiás e Rio Grande do Sul. Foi neste último estado, no segundo período colonial, que o tabaco se constituiu como uma das principais fontes de renda dos colonos alemães. Desta forma, o cultivo foi adotado pelos colonos que chegaram à colônia de São Leopoldo, e aos poucos foi se ampliando para as demais colônias alemãs criadas ao longo do processo de colonização (VENDRUSCOLO, 2017).

No entanto, o maior crescimento da produção ocorreu na colônia de Santa Cruz, onde a produção era feita em pequenas áreas com a utilização da mão de obra e de recursos locais, e que aos poucos foi se especializando melhorando a qualidade para competir com as colônias que tinham melhor acesso ao escoamento do produto. Conforme Vendruscolo (2017, p. 35), “os dados da região demonstram que o tabaco tem importância histórica desde a criação da colônia, sendo um dos produtos mais rentáveis e de maior produção entre os colonos alemães".

Neste momento, dentro do processo histórico da produção de tabaco, ocorre o segundo estágio da história econômica da maioria das regiões que Douglass North apresenta em suas teorias. Nesse estágio, conforme existe a melhoria nos transportes, a região passa a desenvolver algum tipo de comércio e acontece a especialização local (NORTH, 1977). No caso do processo de produção do tabaco, a principal fonte de renda no período era a agricultura, e conforme ocorreram os avanços nos meios de transporte, ocorreu o aumento da produção, bem como a qualidade do produto.

Ao final do século XIX, o mercado europeu absorvia 75\% do tabaco brasileiro. Juntamente com o estabelecimento definitivo da Coroa Portuguesa no país, houve o surgimento das primeiras legislações reguladoras da atividade, em que os produtores tinham que recolher 
impostos incidentes sobre a circulação, a indústria, a produção e o consumo. A tributação era a nível municipal, estadual e federal (HILSINGER, 2016).

Associada à regulamentação da atividade do tabaco está a incidência de impostos e taxas. Os impostos e demais cobranças sobre o tabaco existem desde o período colonial e, no século XIX, foram incrementados, não apenas em suas alíquotas e valores, mas também em sua complexidade, de maneira a ampliar a arrecadação pública sobre o setor que o formava (HILSINGER, 2016, p. 63).

Já nas primeiras décadas do século XX, houve uma concentração espacial do cultivo de tabaco brasileiro, os estados da Bahia e do Rio Grande do Sul se tornaram os produtores de mais da metade da produção, e houve uma redução gradativa nos demais estados. A Bahia mantinha a produção de fumos escuros para a fabricação de charutos, enquanto o Rio Grande do Sul continuava a se especializar na produção de fumos claros com boa qualidade para a fabricação de cigarros (VENDRUSCOLO, 2017).

Segundo Hilsinger (2016), houve uma ruptura baseada no tipo de tabaco cultivado, fator este decisivo para a história da produção de tabaco no Brasil. O que acarretou na mudança do polo produtivo mais dinâmico, que era a Bahia para o Rio Grande do Sul. A produção de fumos claros se sobrepõe aos fumos escuros após 1920. Deste modo, ao longo do século XX, o cultivo passou por um processo de diversificação e de especialização regional, e em paralelo, houve também o desenvolvimento da indústria de beneficiamento e de cigarros.

Portanto, iniciou-se a formação de uma economia própria, ou seja, ao redor da lavoura de tabaco houve a geração de renda e emprego local, uma rede de prestadores de serviços e de infraestrutura. Este é o cenário que Buainain e Filho (2009) destacam como a cultura do tabaco.

O desenvolvimento da indústria de beneficiamento e de cigarros e a economia própria do tabaco que Buainain e Filho (2009) ressaltam, constitui ainda o segundo estágio do desenvolvimento da região. "Surge uma segunda camada da população que começa a gerir modestas indústrias locais para os agricultores. Uma vez que as matérias-primas, o mercado e a mão de obra são supridos originalmente pelas populações agrícolas [...]" (NORTH, 1977, p. 334).

O terceiro estágio da história econômica da maioria das regiões que Douglass North apresenta em suas teorias, é o aumento do comércio inter-regional que faz com que a região se desloque através de uma sucessão de culturas agrícolas (NORTH, 1977). Este estágio já ocorre dentro da produção de tabaco, pois, conforme citado no texto anteriormente, o tabaco, inicialmente, está associado a propriedades diversificadas que também produzem itens de subsistência como arroz, milho e feijão. 
Ao longo do tempo, as pequenas empresas de fabricação de cigarros e charutos, de caráter familiar e artesanal, foram cedendo espaço a fábricas maiores, resultante de associações de empresas ou aquisição de uma pela outra. Portanto, o Brasil viveu nas primeiras décadas do século XX um período de abertura para a chegada de grandes empresas, principalmente, as transnacionais (HILSINGER, 2016).

Este processo de substituição das pequenas indústrias familiares pelas fábricas de cigarros representa o quarto estágio da história econômica da maioria das regiões, que é a industrialização. Nesta fase, a região é forçada a se industrializar, e os primeiros estágios da industrialização baseiam-se tipicamente em produtos agrícolas e florestais (NORTH, 1977).

A criação e instalação de fábrica de cigarros dinamizaram as interações locais, promovendo mudanças nas relações de produção, principalmente com a criação do Sistema Integrado de Produção de Tabaco (SIPT), o qual seria intensificado a partir da década de 1960. O SIPT, somado a outras dinâmicas [...] levou à consolidação de um Complexo Agroindustrial Fumageiro (CAIF), com significativo aumento da produção de tabaco para a exportação e da produção de cigarros, principalmente com as fusões empresariais e a instalação de novas empresas na região fumageira de Santa Cruz do Sul (VENDRUSCOLO, 2017, p. 36).

A partir de 1918, a produção de tabaco foi intensificada no Rio Grande do Sul, especificamente no Vale do Rio Pardo, com o surgimento do primeiro polo industrial fumageiro. O crescimento do comércio de cigarros no Brasil e no exterior impulsionou a fumicultura, o que levou desenvolvimento e crescimento populacional para Santa Cruz do Sul, que concentrava empresas nacionais e internacionais (BELING, 2006). Foi quando a British American Tobacco (BAT) associada à Souza Cruz (criada em 1903 no Rio Janeiro) se instalou em Santa Cruz do Sul, bem como outras indústrias ao longo dos anos (VENDRUSCOLO, 2017).

Havia motivos para levar a Souza Cruz até o município de Santa Cruz do Sul, sendo eles: terras propícias para o cultivo do tabaco de estufa, bem como clima e chuvas distribuídas ao longo do ano; produção e experiência familiar em pequenas propriedades; perfil dos produtores; importância da região na produção do tabaco; e estrada de ferro como meio de transporte (VOGT, 1997). Estes motivos representam as vantagens locacionais da teoria da localização, em que caraterísticas da região e redução dos custos de transporte são fatores que determinam uma base de exportação de produtos manufaturados, e consequentemente, o desenvolvimento regional (NORTH, 1977). O desenvolvimento e o crescimento populacional interpretado pelas teorias de Douglass North remetem ao processo de urbanização. De acordo com o autor, este processo é parte integrante do crescimento das regiões manufatureiras (NORTH, 1977). 
As guerras na Europa tiveram influência no consumo de tabaco, mas foram as Guerras Mundiais que promoveram em grande escala o uso do cigarro. Com a industrialização, o custo de fabricação dos cigarros se tornou mais barato e o processo mais rápido, levando a uma produção em massa. Consequentemente, este processo tornou o cigarro mais acessível aos consumidores. Além disso, os meios de comunicação (filmes e propagandas) também tiveram forte contribuição para o aumento do consumo de cigarros em nível mundial (HILSINGER, 2016).

A Segunda Guerra Mundial gerou dificuldades de exportação para os países em guerra, como a Alemanha, o que levou a diminuição da produção de tabaco ao final dos anos 1940 (VENDRUSCOLO, 2017). Em contrapartida, outro acontecimento importante foi ao final dos anos 1960, a crise de produção de tabaco na Rodésia (atual Zimbábue) que abriu espaço no mercado internacional onde havia demanda crescente (BUAINAIN; FILHO, 2009).

E assim, a indústria brasileira de tabaco estava em condições para aproveitar a oportunidade devido ao processo de modernização da agricultura iniciado na década de 1960, "a mecanização, os novos insumos e, principalmente a relação com os fornecedores e compradores, impulsionaram o aumento da área cultivada do tabaco, bem como o aumento da produtividade" (VENDRUSCOLO, 2017, p. 36). No mesmo sentido, devido à capacidade de coordenar a complexa rede de suprimento integrada por milhares de agricultores familiares.

A década de 1970 marcou a entrada de maior investimento estrangeiro no setor, destinado principalmente à tecnologia de produção com o objetivo de aumentar a qualidade do tabaco para a produção de cigarros. O período também marca a consolidação da região Sul como a principal região produtora de tabaco do Brasil, com destaque para a microrregião de Santa Cruz do Sul, que passou a concentrar o maior parque industrial de beneficiamento e de exportação de tabaco do mundo (HILSINGER, 2016).

Neste momento, quando o Brasil começa a exportar tabaco para o comércio internacional, atinge-se o quinto estágio da história econômica da maioria das regiões, que representa a etapa final do desenvolvimento regional, quando a região passa a produzir para a exportação. Deste modo, o sucesso das exportações é que resultará no crescimento da região (NORTH, 1977).

Um dos pontos importantes que Douglass North atribui para as regiões chegarem até este estágio é o custo de transporte, conforme o processo da produção de tabaco foi evoluindo ao longo dos anos, é possível analisar que o desenvolvimento ocorreu em regiões que tinham fácil acesso ao escoamento da produção. No que tange a distribuição da renda, North $(1977$, p. 341) 
diz que "a base de exportação desempenha um papel vital na determinação do nível de renda absoluta e "per capita" de uma região".

O processo de modernização gerou mudanças em toda a cadeia de produção do tabaco, desde a propriedade de terra até a distribuição da renda. Essas mudanças envolveram a introdução do tabaco de estufa e de forno, o uso de adubos, inseticidas e agroquímicos, bem como assistência técnica para capacitar os produtores (BUAINAIN; FILHO, 2009). Assim, a presença das lavouras passou a se estender para novos municípios dos estados do Rio Grande do Sul, Santa Catarina e Paraná, e como consequência, o desenvolvimento das oportunidades de exportação atraiu capital estrangeiro para o setor, foram muitos investimentos na produção e na industrialização (VOGT, 1997).

\subsection{Institucionalismo econômico e a path dependence}

A reestruturação da indústria do tabaco, assim como a entrada de novas empresas levou a institucionalização do sistema de produção integrado, implantado informalmente pela Souza Cruz em 1918. O Sistema Integrado de Produção de Tabaco foi criado como forma de melhorar o sistema, a definição dos preços e as regras básicas de regulação do setor começaram a ser formalizadas e definidas através de negociações com os representantes da classe: Sindicato da Indústria do Fumo do Rio Grande do Sul (atual SINDITABACO), a AFUBRA, e posteriormente, as Federações dos Trabalhadores. Outro ponto importante está relacionado com a segurança e a confiança do produtor em relação à indústria, este sistema seria uma forma de estimular a adesão à produção de tabaco (BUAINAIN; FILHO, 2009).

O SIPT foi criado com o intuito de melhorar a qualidade do produto através de inovações de sementes e técnicas de secagem com vistas à produção de cigarros, e assim, dispunha de financiamentos e assistência técnica para os agricultores, garantindo, posteriormente, a compra integral da safra contratada. Por meio deste sistema, os agricultores recebem da indústria as sementes e os demais insumos necessários à produção, bem como as instruções sobre o plantio (SILVA, 2002).

Desta forma, a integração entre os produtores e as empresas ocorre por meio de um contrato, com o intermédio do orientador técnico, que realiza visitas periódicas nas propriedades, acompanhando a produção, fazendo estimativas e prestando a assistência técnica necessária. A inserção do orientador técnico nas propriedades tem a função principal de vender os insumos necessários, garantindo o contrato com a empresa e o controle da comercialização 
ao final da safra (VENDRUSCOLO, 2017). Portanto, enquanto a indústria fornece insumos, investimentos em infraestrutura e assistência técnica, o produtor se compromete em produzir o tabaco nos padrões de qualidade exigidos pela indústria e a exclusividade de comercialização (DUTRA; HILSINGER, 2013).

Segundo North (1994), o desenvolvimento regional pode ser visualizado a partir do desenvolvimento das instituições e do modo que elas afetam a economia. Os institucionalistas consideram o desenvolvimento como uma forma de evidenciar diferentes graus de desempenho econômico, desta forma, North se refere ao desenvolvimento como crescimento econômico no trabalho de 1994.

As instituições estão no centro do processo de desenvolvimento e evolução da sociedade, são as restrições e as regras sociais estabelecidas que podem ser formais ou informais, e as suas características são de execução e estrutura de interação. Diante disso, o conceito da path dependence está condicionado à formação e a evolução dessas instituições. Assim, estudar a história e a evolução econômica de uma sociedade ou setor é explicar suas instituições como determinantes do desempenho econômico. Nesse sentido, não se criam, mas continuam sendo reproduzidos "velhos" padrões de comportamento e de conceitos que não se diferenciam dos anteriores. Por isso, o papel da path dependence é determinante no modo como os atores vão agir frente às incertezas (NORTH, 1990).

A importância da análise histórica reside no reconhecimento de que o momento presente das instituições condiciona o seu desenvolvimento futuro, e assim, o conceito da path dependence se vincula ao processo de mudança institucional. Deste modo, a path dependence pode ser entendida como uma explicação à predisposição à mudança para alterar ou não padrões já existentes, considerando que o contexto histórico é importante para o entendimento das escolhas atuais, pois, refletirão no futuro das instituições. Essas escolhas são vistas como formas de restrição, constituindo-se em restrições formais - regras, leis, constituições, e restrições informais - normas de comportamento, convenções, código de conduta auto imposto (NORTH, 1990).

As mudanças econômicas ou sociais, por exemplo, são transformações institucionais que ocorrem pela alteração dos hábitos mentais. A mudança não é um processo fácil, pois, atua a partir de um processo de escolha e de adaptação das instituições ao ambiente nas quais estão inseridas (VEBLEN, 1983).

As instituições são como firmas, mercados e relações contratuais quando se comportam e se relacionam, a partir da maneira como estão arranjadas na sociedade, caracterizando sua 
eficiência ou não. Desta forma, o desenvolvimento das instituições pode fornecer condições apropriadas para orientar os agentes a encontrarem formas de organização, auxiliando no melhoramento do desempenho econômico. Um dos papéis das instituições é impor a ordem e reduzir as incertezas oriundas das transações que realiza (WILLIAMSON, 1985).

A path dependence também permite identificar processos de mudanças e de organização estrutural, quer em estruturas tecnológicas ou em instituições. Entretanto, isso dependerá do caminho que foi trilhado ao longo do tempo para a trajetória atual, bem como de incentivos do Estado, como, por exemplo, por meio de políticas (NORTH, 1990).

A partir desta breve contextualização teórica sobre o Institucionalismo Econômico, cabe notar que a produção de tabaco está presente no Brasil desde o início do século XVI, e foi responsável pelo destaque do Brasil no cenário internacional, sendo o segundo maior produtor mundial de tabaco e líder em exportações desde o ano de 1993 (SAITO et al, 2018). Desde então, mesmo diante de movimentos contrários à produção e ao consumo de tabaco, os produtores rurais se mantiveram na mesma trajetória que os seus antepassados, ou seja, o cultivo vem sendo passado de geração para geração. E conforme North, a tendência é que assim permaneça, pois, "as decisões tomadas no passado têm, portanto, forte influência sobre as possibilidades do presente" (GALA, 2003, p. 104).

Outro ponto é quanto ao Sistema Integrado de Produção de Tabaco, pois, diante desta relação entre o agricultor e a empresa fumageira, existem duas instituições: uma instituição formal, representada pelo contrato de compra; e uma instituição informal representada através da relação entre o produtor e o orientador técnico. Primeiro, o contrato é uma certa garantia da contratação da produção de tabaco por parte da empresa, onde o agricultor se compromete a produzir, e a empresa se compromete a comprar conforme os preços negociados pelas entidades do setor. Em segundo lugar, o orientador técnico é quem representa a empresa no campo, e é importante existir uma relação de amizade e confiança com o produtor, de modo que assim ele produzirá e comercializará sua produção conforme o que ficou estabelecido através do contrato.

Por outro lado, esta relação estabelecida pelo SIPT pode ser considerada como uma dependência de trajetória, onde os produtores podem continuar produzindo tabaco, historicamente, conforme as suas gerações anteriores, devido a segurança e a garantia que o contrato promove. Independentemente se a cultura gera bons resultados financeiros ou não, a partir da formalização do contrato, a empresa fumageira se compromete com a compra do tabaco que será produzido, e com o fornecimento dos insumos e da assistência técnica necessários para a produção de acordo com as quantidades estipuladas no contrato. 


\section{Crítica ao trabalho de North}

Segundo Paiva (2004), para identificar o potencial de uma região é necessário identificar setores que geram maior benefício por unidade de custo, o que a região possui e não utiliza com o objetivo de maximizar o rendimento potencial. É a capacidade de dar início e sustentação a processos que visem a mobilização do maior volume de recursos disponíveis internamente, e "[...] um processo de crescimento onde os determinantes do sucesso e da competitividade de longo prazo vão sendo endogeneizados de forma crescente pelas firmas e pelos agentes produtivos locais" (PAIVA, 2004, p. 16). Além disso, a determinação do potencial regional também diz respeito à divisão regional e internacional do trabalho e à especialização.

E assim, a especialização regional acaba sendo considerada um importante indício do potencial de uma região, pois, é um fator que representa as vantagens que uma região possui diante de outras na produção de determinado bem ou produto. A especialização amplia a competitividade e diminui os custos com base na disponibilidade dos recursos e na participação da mão de obra regional (PAIVA, 2004).

Neste momento, Paiva (2004) faz sua primeira crítica ao trabalho de North, pois, destaca que em termos de desenvolvimento regional, é necessária a diversificação produtiva do território. E que toda economia especializada bem-sucedida é uma economia diversificada no plano produtivo, pois, “[...] endogeneizou o controle sobre os recursos produtivos e o excedente econômico [...] toda a especialização regional deve ser pensada em sua dimensão de "cadeia"”", pois, é uma fonte de risco e incerteza (PAIVA, 2004, p. 21).

\footnotetext{
Em termos práticos, a especialização é condição da rentabilidade, a diversificação é condição da segurança. O equilíbrio entre esses dois objetivos será encontrado quando a especialização se realizar em mais de um produto-núcleo, mas não em um número tão grande que inviabilize a mobilização de recursos suficientes para que se atinja a escala mínima competitiva necessária à conquista de vantagens absolutas sobre a produção dos vizinhos (PAIVA, 2004, p. 22).
}

Uma economia mercantil que não internalizou um departamento produtor de bens de capital é uma economia que tem sua dinâmica determinada pelas exportações. Isto se deve ao fato de que os processos de produção, de comercialização e de financiamento do setor são controlados desde dentro, portanto, os efeitos multiplicadores e aceleradores da demanda externa tendem a ser internalizados gradualmente. Deste modo, o processo de desenvolvimento é endógeno, e mesmo que o ponto de partida seja o dinamismo externo, cabe observar que o 
motor inicial é exógeno, e consequentemente, a dinâmica interna é dependente (MELLHO, 1982 apud PAIVA, 2008).

A especialização produtiva regional não planejada (sem o monitoramento e a depressão da volatilidade associada à dependência de um produto e/ou de um mercado, mas que apresenta rendimentos e dinâmicas fortemente correlacionados) é ponderada como arriscada e deve ser evitada; já a especialização produtiva regional controlada desde dentro e planejada (com vistas a volatilidade da renda dos agentes internos) é um "instrumento de alavancagem da mercantilização, da urbanização, da divisão do trabalho e da produtividade daquelas regiões marcadas pela estreiteza do mercado interno e pelo elevado grau de autarquização das estruturas produtivas rurais" (PAIVA, 2004, p. 25).

Outra crítica está relacionada à teoria de Smith, que aponta fundamentos do modelo de desenvolvimento regional de Douglass North. Para Smith, a transformação da relação entre tamanho de mercado e divisão do trabalho como um fator de alavancagem do desenvolvimento é possível somente através da solução exportadora. Para isso, as regiões que ingressam em um padrão de desenvolvimento para fora, tornam sua dinâmica interna mais dependente da dinâmica das regiões com as quais são estabelecidas relações comerciais (PAIVA, 2004).

\section{Considerações finais}

A cultura do tabaco constitui um importante capítulo na história do Brasil, presente no cenário econômico desde o início do século XVI, contribuiu para o desenvolvimento das regiões produtoras. Pois, o crescimento de uma região é consequência dos resultados da sua base de exportação e isso se deve aos fatores locais que viabilizaram o desenvolvimento de produtos primários.

Diante disso, ao longo dos anos ocorreu a formação de uma economia própria do tabaco, de modo que em torno da lavoura houve a geração de renda e emprego local, uma rede de prestadores de serviços e infraestrutura. E assim, a partir da modernização do processo produtivo e das oportunidades do mercado internacional, o tabaco produzido no Brasil conquistou destaque no cenário externo e atraiu investimentos estrangeiros. Neste contexto, houve um incremento na produção de tabaco no país no final do século XX e no início do século XXI, o que levou o país a conquistar o lugar de segundo maior produtor mundial de tabaco e o líder em exportações desde o ano de 1993. 
A partir do levantamento sobre a trajetória sócio histórica da produção de tabaco no Brasil, entende-se a importância desta cultura em uma trajetória histórica de desenvolvimento das regiões produtoras e de inserção da produção no mercado internacional, com a oferta de um produto diferenciado e com qualidade brasileira.

Entretanto, em termos de desenvolvimento regional, é necessária a diversificação produtiva do território, pois, a diversificação é uma condição de segurança para a região. Desta forma, torna-se necessário mais do que uma base exportadora, mas principalmente, a capacidade de desenvolvimento do mercado externo, para não tornar a dinâmica interna dependente da dinâmica das regiões com as quais são estabelecidas as relações comerciais.

Por fim, entende-se a velocidade das mudanças no mundo contemporâneo como um fator primordial na concepção atualizada de desenvolvimento regional, onde os contextos econômicos se tornam abertos e transformados por meio da revolução científica e tecnológica. Esse novo cenário é consequência de dois processos contextuais.

Com o caráter econômico, o primeiro é a abertura externa causada pela globalização, para isso, é necessário tornar as exportações mais modernas através do progresso técnico - o que agrega valor ao preço final, e competitivas - por meio da participação em segmentos produtivos e em expansão. Já o segundo processo contextual é a abertura interna impulsionada pela descentralização. De caráter político, este processo é uma tendência mundial que está atrelada a privatização e aos sistemas descentralizados de tomada de decisão. Deste modo, conclui-se que a tendência de desenvolvimento regional é um cenário equitativo a partir da participação interna e considerando os benefícios da abertura externa.

\section{Referências}

BELING, Romar Rudolfo. A história de muita gente: um exemplo de liderança. Santa Cruz do Sul: AFUBRA, 2006.

BUAINAIN; FILHO. Organização e funcionamento do mercado de tabaco no Sul do Brasil. Campinas: Editora da Unicamp, 2009.

DUTRA, E. J.; HILSINGER, R. A Cadeia produtiva do tabaco na região Sul do Brasil: aspectos quantitativos e qualitativos. Geografia Ensino \& Pesquisa, vol. 17, n. 3, set./dez. 2013. Disponível em: <https://periodicos.ufsm.br/geografia/article/view/12490>. Acesso em: 21 set. 2019.

GALA, Paulo. A Teoria Institucional de Douglass North. Revista de Economia Política, vol. 23, no 2 (90), abril-junho/2003. Disponível em: <http://www.rep.org.br/PDF/90-6.PDF>. Acesso em: 29 out. 2019. 
GIL, Antônio Carlos. Técnicas de pesquisa em economia. 2. ed. São Paulo: Atlas, 1991.

HILSINGER, Roni. O território do tabaco no Sul do Rio Grande do Sul diante da Convenção Quadro para o controle do tabaco. Tese de Doutorado (Programa de Pós-Graduação em Geografia). Universidade Federal do Rio Grande do Sul. Porto Alegre: 2016, 223 p. Disponível em: <https://lume.ufrgs.br/handle/10183/148765/>. Acesso em: 15 set. 2018.

NORTH, D. C. Custos de Transação, Instituições e Desempenho Econômico. Rio de Janeiro: Instituto Liberal, 1994.

Institutions, institutional change and economic performance. Cambridge, EUA: Cambridge University Press, 1990.

Teoria da localização e crescimento econômico regional. In: J. SCHWARTZMANN (org.)

Economia regional e urbana: textos escolhidos. Belo Horizonte: UFMG, p. 333- 343, 1977.

Disponível em: <http://files.luciralves.com/200000057-

aaf23abec7/teoria_da_localizacao_e_crescimento_economico_regional.pdf $>$. Acesso em: 16 nov. 2018.

PAIVA, Carlos Águedo Nagel. Demanda efetiva e desenvolvimento regional. REDES, Santa Cruz do Sul, v. 13, n. 2, p. 161 - 183, mai./ago. 2008.

Como Identificar e Mobilizar o Potencial de Desenvolvimento Endógeno De Uma Região? Porto Alegre: FEE, 2004. Disponível em:

$<$ http://cdn.fee.tche.br/documentos/documentos_fee_59.pdf >. Acesso em: 08 de outubro de 2019.

SAITO, Camila et al. Relevância do Setor de Tabaco no Brasil. Tendências Consultoria Integrada. Jul. 2018. Disponível em: <http://www.sinditabaco.com.br/site/wpcontent/uploads/2018/10/Estudo-Tende\%CC\%82ncias_Releva\%CC\%82ncia-do-setor-detabaco-no-Brasil.pdf>. Acesso em: 03 ago. 2019.

SILVA, L. X. Análise do Complexo Agroindustrial Fumageiro sul-brasileiro sob o enfoque da economia dos custos de transação. Tese (Doutorado em Economia). Faculdade de Ciências Econômicas, Universidade Federal do Rio Grande do Sul: Porto Alegre, 2002, 287 p. Disponível em: <http://www.ufrgs.br/pgdr/publicacoes/producaotextual/leonardo-

xavier\%20da\%20silva/silva-leonardo-xavier-da-analise-do-complexo-agroindustrial-fumageirosul-brasileiro-sob-o-enfoque-da-economia-dos-custos-de-transacao-porto-alegre-ufrgs-2002287p-tese-de-doutorado-em-economia>. Acesso em: 01 set. 2019.

SINDITABACO. Sindicato Interestadual da Indústria do Tabaco. 2019. Disponível em: <http://www.sinditabaco.com.br/>. Acesso em: 01 ago. 2019.

VENDRUSCOLO, Rafaela. Instituições e Críticas na fumicultura do Rio Grande do Sul: mudanças e reafirmações institucionais. Porto Alegre: Universidade Federal do Rio Grande do Sul, 2017. Disponível em: <https://lume.ufrgs.br/handle/10183/172447/>. Acesso em: 01 set. 2018.

VEBLEN, T. A teoria da classe ociosa: um estudo econômico das instituições. São Paulo: Abril Cultural, 1983.

VOGT, Olgário Paulo. A produção de fumo em Santa Cruz do Sul - RS (1849-1993). Santa Cruz do Sul: EDUNISC, 1997.

WEISS, Carla. As mudanças no ambiente institucional formal e o direcionamento da cadeia agroindustrial do tabaco no RS. Dissertação de Mestrado (Programa de Pós-Graduação em Agronegócios do Centro de Estudos e Pesquisa em Agronegócios - CEPAN). Universidade Federal do Rio Grande do Sul: Porto Alegre, 2015, 130p.Disponível em: 
<https://lume.ufrgs.br/bitstream/handle/10183/163314/001024222.pdf?sequence=1\&isAllowe $\mathrm{d}=\mathrm{y}>$. Acesso em: 01 ago. 2019.

WILLIAMSON, O. The Economic Institutions of Capitalism. New York: Free Press, 1985. 